Article

\title{
Consumer Preferences of Locally Grown Specialty Crop: The Case of Taiwan Coffee
}

\author{
Jong-Wen Wann, Chia-Yung Kao and Yu-Chen Yang * \\ Department of Applied Economics, National Chung-Hsing University, Taichung 402, Taiwan; \\ jwwann@nchu.edu.tw (J.-W.W.); njik789@alumni.nchu.edu.tw (C.-Y.K.) \\ * Correspondence: ycyang@dragon.nchu.edu.tw
}

Received: 27 April 2018; Accepted: 5 July 2018; Published: 10 July 2018

\begin{abstract}
The role of retailers in the local coffee niche market is to add value with unique characteristics such as creativity, cultural identity, and innovation in order to differentiate their products. Producers/retailers can provide customized services for special products according to different consumer preferences and needs. They can gain the trust and loyalty of consumers in this way. This study aims to understand consumer assessments of the different attributes of local specialty coffee provided by coffee retailers in order to help them develop strategies for increased sales in the niche market. Regarding internal quality, atypically, as the empirical results of conjoint analysis has shown, Taiwanese consumers do not prefer the attributes of coffee such as extra aroma and strong acidic taste. Therefore, they are not willing to pay the premium for these attributes. With regards to external quality, consumers prefer the attributes of specialty café style and product featured packaging.
\end{abstract}

Keywords: locally grown crop; coffee; conjoint analysis; willingness to pay; discrete choice method

\section{Introduction}

While facing a strong competition from imported low price coffee (retail price of imported coffee ranges from 500-800 NTD per lb.), Taiwan's specialty coffee niche market is emerging due to the efforts of locally grown product retailers (including producers in the integrated marketing chain). As the knowledge, information, and living standards have improved, high-quality coffee has gradually emerged. In 2011, the average Taiwanese person's coffee consumption was $1.09 \mathrm{~kg}$, as compared to the global per capita of $1.3 \mathrm{~kg}$. However, there is still much room for greater future consumption compared to that of neighboring Asian areass. In response to changes in consumer preferences, the amount of coffee grown in Taiwan has been increasing since 2001. Producers and retailers have increased their knowledge and devoted themselves to the cultivation and management of their coffee and businesses. Local Taiwanese coffee eventually appeared in the marketplace in 2009. Production costs of local coffee are too high to compete with foreign producers. Therefore, it has been necessary to explore and distinguish specialty products/markets from the mainstream in order to increase the added value for attracting of the participation of producers and retailers.

The expansion of the local coffee industry can be shown from the following industrial data; the plantation area of coffee in Taiwan has increased from 387.57 acres in 2006 to 1104.22 acres in 2016; the aggregated production has increased from 256.55 tons in 2006 to 840 tons in 2016 . The output level of local coffee has increased nearly three times over the past decade. The farm level price of coffee has risen tremendously from 50 NTD/kg in 2005 to 925 NTD/ $\mathrm{kg}$ in 2016 [1]. This indicates a shift in consumer's preference toward the local coffee.

A niche market refers to one that has special consumer needs/demands yet to be completely fulfilled [2-7]. The niche market's scope is relatively small compared to the mainstream market. 
In order to avoid strong price competition within the market, niche producers focus more on the quality required by consumers in order to gain higher profits. Correspondingly, niche market customers are also more willing to pay more to meet their own needs/preferences [8-10]. Kotler stated [7] that the market is made up of consumers and will be exposed to different behaviors in terms of ideas, resources, growing areas, and buying habits. Retailers have to develop the characteristics in demand in or to be distinguished from the others in the niche market [11-13].

Governments have focused on the issues in the development of the local food system (LFS). Consumers' needs for the attributes of locally grown agricultural products has become of particular interest. Local consumerism has become increasingly widely spread in local agricultural products [14]. As the local people increase their consumption of daily coffee, the potential to consume greater locally grown coffee in the future can be realized if consumers' preferences are known. Currently, the tertiary industry in Taiwan's coffee industry has been well developed and provides consumers with multiple services. The development strategy of the local coffee industry primarily focuses upon how retailers and producers can identify and cater to consumer groups who recognize and appreciate their products' unique characteristics.

At present, the development of leisure garden coffee houses is also quite rapid. Such cafés tend to feature unique cultural flavors [1]. The Taiwanese government hopes to combine local diversified products and cultural characteristics with coffee vending; localization of agriculture has been realized in daily life.

In recent years, the types or styles of coffee shops have become quite diverse. Cafés are rapidly growing in various cities to distinguish themselves from other buildings in the area. The ambiance/style of cafés can be divided into three categories: Traditional architecture, natural landscape, and creative personality. The whole niche coffee market is not designed to meet the needs of the public yet; it is relatively easy to create uniquely styled buildings and/or environments to obtain greater market share in the specialty coffee arena.

The retailers also pay much attention to coffee packaging. The characteristics of product packaging can provide other features. Currently, mainstream coffee products place less emphasis on packaging; instead, they focus on the quality of the main product. In order to fulfill the specific consumers in the niche market, coffee retailers integrate local culture, customs, and geographical landscape features into the packaging. With the creative development of young native ethnic groups, hand-painted designs have gradually become popular.

Regarding the internal quality, local coffee retailers can provide special scent descriptions to attract consumers. They can relay various flavors such as flowery, fruity, nutty, and woody. Retailers provide different flavors of coffee in order to differentiate their products. A cup of coffee can be judged in terms of taste, smell, and touch. The intensity of acid is affected not only by the conditions of the growing climate, but also by the post-harvest processing, baking, and brewing methods [1]. Additionally, the acidity level will affect the extent of the brewing process.

Usually, the locally grown coffee is sold at cafés with tables that consumers can sit down and drink a cup of coffee; this is part of their buying, social, and consumption experience. The cafés also have shelves that sell locally grown coffee beans or coffee powders. Some cafés have an area which only features specialty locally grown coffee beans. The types or styles of coffee shops have become quite diverse in Taiwan. Consumers in cafés or coffee shops have expressed enjoying the atmospheres featuring local culture and special ambiance/architectural styles created by coffee retailers. Hence, we agree that that while the selling/consumption environment may not be an attribute of the coffee product specifically, such does however serve to meet (or otherwise not) the preferences of consumers in their local coffee culture/experience [15].

The development of the local coffee market can promote the principle of appropriateness. Taiwan's natural environment is very suitable for growing coffee. However, due to the principle of comparative advantage; Taiwan's current coffee consumption is mainly imported. Under the globalized food supply chain providing low priced products, a short local coffee supply chain cannot exist easily. 
There have to be people that promote local coffee short supply chains which are more environmentally friendly and can contribute to rural development by increasing local employment; most important is to balance the supply chain gap between urban and rural areas. Rural development also can prevent the outmigration of workers and business from the agricultural to urban sectors. Since most of the locally grown coffee is from smallholder family type farms, the major employers are in the rural area and likewise serve as the retailers in vertically integrated marketing chains. Intermediate-level waste does not exist.

Currently, the marketing systems of locally grown coffee are more akin to the way of direct selling. Usually, the producers of coffee also run a coffee shop or café to sell their product. In these stores, the producers or retailers can communicate directly. In this case, the consumers know where the coffee farms/producers are and the ways they produce coffee beans. Marketing in this way, coffee producers and consumers are reconnected, which has positive implications for meeting social and environmental interests, while at the same time promoting local regions for added benefits, such as tourism/eco-tourism [15]. In summary, the public has become more focused on enjoying a greater quality of life. Coffee has become an integral part of Taiwanese lifestyles. The local coffee market is still growing though has not reached it maximum potential. Before deciding on the products or market development strategies to be adopted, smallholder farmers or retailers do not think from the viewpoint of production orientation. Instead, they are trying to rely on the needs of customers to achieve increased market share [16]. This study aims to understand consumer assessments of the different attributes of local specialty coffee provided by coffee retailers. It also estimates the willingness to pay for each product's attributes currently provided by retailers in order to help them develop strategies for increased sales in the niche market. Once local producers understand the potential preferences of consumers, they can fulfill the consumer preferences through process adjustment, marketing, or R\&D in technological development. However, the retailer and wholesalers in the global supply chain have not made such adjustments per local demand/preferences. They have not adjusted their quality according to the preference of Taiwanese consumers. Therefore, as a main takeaway, local producers/sellers who do have this information (such as from our research) and apply it to the local niche markets, will have a distinct advantage over international (and local) entities, which do not.

\section{Literature Review}

Conjoint analysis (CA) is a method used to assess consumer preference for different product attributes; it is also called Multi-Attribute Valuation (MAV). In Multi-Attribute Valuation (MAV), the respondents are required to make a choice. Their selection can be the choice of which alternative set that they prefer; this is called choice based conjoint analysis [17]. Alternatively, they may provide a measurement of the available alternatives; this is rate based or score based conjoint analysis $[18,19]$. In the early stage of conjoint analysis, there is no economic theory background [18]. The theoretical background of choice experiments is random utility models; the random utility model was developed by McFadden [20]. In this theory, the consumer's direct utility is the sum of a deterministic term (which is a function of the attributes and consumer's socioeconomic characteristics) and a random error term. However, some researcher claimed that discrete choice experiment and conjoint analysis are two different methods [21].

This method has been applied to certain specific coffee markets. Jervis et al. conducted [22] a conjoint analysis of consumers in different groups using latte coffee, where the set of product attributes included the place of purchase, milk content, fat content, sweetness, and other tastes. According to the results, consumers were divided into three types of groups: One of which milk content and fat content affected their consumption habits; the second group care about the café style/ambiance; and the third group had higher health awareness. Their study also found that the information provided by latte coffee consumer behavior and product choice can be used to analyze the factors that determine purchases. The culture coffee buying environments was found to be the most influential factor of purchases. 
Some researchers are regarding with coffee with fair trade label in different countries. Arnot et al. (2006) [23] used a conditional logit model to analyze the price effect on fair trade labeled coffee. In their study, by cooperating with a vendor at the university, an experimental design was performed in a real world market situation in order to reveal consumer preferences for fair trade coffee. Their results showed that the price elasticity of fair trade coffee was smaller than conventional coffee. This implied that when fair trade labeling increased the price of coffee, consumer responses were smaller than when conventional coffee prices increased. The traditional attributes of coffee sold by the vendor included the degree of roasting, aroma, the country of origin. The other socioeconomic variable such as gender is also included in the conditional logit model. Gender had no impact on the preference for fair trade coffee. A person who is familiar with the fair trade concept is more willing to purchase fair trade coffee. Their findings also showed that the ethical attribute as possibly being the major motive for most consumers to purchase fair trade labeled coffee. Consumers wanted to participate in the fair trade campaign by purchasing the products that could benefit coffee growers.

Basu et al. (2008) [24] investigated consumers' willingness to pay for products with fair trade labels in the US and Germany. This research is the first one to investigate country level differences in consumers' preferences for fair trade labeling. In their study, a blocked experimental design technique was applied for the selection of 15 sets of five questions in gathering choice data; a conditional logit model was used to estimate consumers' preference for fair trade labeled coffee. The attributes of coffee investigated in the study included traditional coffee attributes (i.e., price and country of origin). In addition, the other attributes such as organic, labeling certifiers, and performance attributes such as increased growers' revenue and increase grower's participation were also investigated. Their results showed that the information contained in the label can affect the consumers' premium to pay for the fair trade label. Consumers preferred the label that increased participants' income. However, if the income of participants increased more than a certain threshold, consumers were concerned over the issue of inequality; this was because the label only increased the participants' income, though after a point was seen as raising the gap in income levels between participants and non-participants.

Cranfield et al. applied [25] conjoint analysis to consumers' preferences for the attributes of fair trade coffee in Toronto and Vancouver. The results showed that consumers in both regions paid great attention to product premiums and label descriptions. Consumers in Toronto placed an emphasis on labeled products, while consumers in Vancouver favored both certified organic and fair trade labeled products.

De Pelsmacker et al. (2005) [26] investigated Belgium consumer preferences for different attributes of coffee ethical labeling. By using conjoint analysis, consumer preferences for the attributes of labeled coffee investigated included the type of label, label issuer, label information, distribution, promotion, and branding. Using a web survey to collect the experimental data for consumer preferences, the relative importance of attribute levels was determined. The results showed that the type of label was the most import attribute, followed by distribution method and the issuers of labels. For the attribute of label type, their empirical results indicated that consumers preferred fair trade labels to eco and bio labels. Among the attribute of label issuers, consumers preferred those certified by European government or by non-governmental organizations to those provided by local government. For distribution strategy, consumers preferred labeled products which were no co-located with non-labeled products. They want labeled products to be placed in a specialty group in order to avoid the effort in scanning/identifying labeled and non-label products. The brand imagine had relatively less importance in affecting consumer preference for labeled products.

Rotaris et al. (2011) [27] used a stated preference data collection method to investigate the factors that affected Italian consumer choices of coffee products. In this research, the mixed logit models with error components were used. Their results showed that brand name was the most important factor that affected consumer choice. The other facets, such purchasing habits and price also could affect consumer preferences for coffee products. However, the effects of brand name, habits, and price were affected by consumer socioeconomic factors. The sensitivity for price change was affected by age, 
gender, and education level. Consumer willingness to pay for fair trade coffee was affected by gender, age, education level, job, and purchasing habits. The average willingness to pay was approximately 2.2 euros.

Asioli et al. (2016) [28] used two different conjoint methods (CBCA choice based and RBCA rate based) to investigated Norwegian consumer preferences for iced coffee. The attributes for iced coffee products included coffee type (latte, espresso), calories $(60,90)$, origin (Norway, Italy), and price $(2,3$, 3.4 euros). The selected socioeconomic variables including gender and age were also included in the ANOVA rating model. For the random utility model, the attributes and selections were the same. The empirical results from the two different methods were similar.

Wann et al. (2016) [14] investigated consumers' willingness to pay for different attributes of locally grown vegetable and fruit in Taiwan. By using conjoint analysis, their results showed that consumers' education levels had an effect on their willingness to pay for different attributes of locally grown vegetable and fruit. Consumers with higher education levels are willing to pay more for safety than for freshness. Consumers with lower education levels are willing to pay more for freshness than for food safety. In addition, consumers are willing to pay for attributes of cultural identity and environmental protection. However, the preference of consumers for different attributes of locally grown coffee has not been widely investigated. To fill this gap, we conduct a research on the consumers' preference for locally grown coffee.

\section{Materials and Methods}

\subsection{The Survey}

A total of 300 survey questionnaires were disseminated to consumers in the Taichung area. The purposive sampling method was used to survey those who had experience in consuming locally grown specialty coffee. We surveyed consumers in the coffee shops or cafés that sell locally grown coffee. The survey period was between April and May 2015. 250 questionnaires in total are returned, among which 245 questionnaires were completed. The owners or managers of the coffee shops or cafés at which we conducted the survey stated that their view of the future of local coffee was quite optimistic.

The socioeconomic characteristics of the respondents are shown in Table 1. The respondents are divided into rural and urban groups according to the locations where they lived. Overall, 53.91 percent of respondents were women and 46.09 percent were men. Most of our respondents were between 20 and 50 years old. The percentage of respondents whose age was between 21 and 30 years old is the highest (36.36\%). Regarding respondents' education level, most of our respondents have college degrees or higher. Regarding respondents' professions, 26.34 percent were engaged in the service industry, followed by those who were government employees (16.87\%). Most of our respondents' monthly incomes were less than 60,000 NTD. The percentage of respondents, whose monthly incomes were between 20,000 and 40,000 NTD is the highest (36.21\%), followed by those whose monthly income is less than 20,000 NTD (25.1\%).

Table 1. Socioeconomic characteristics of respondents.

\begin{tabular}{|c|c|c|c|c|c|c|c|}
\hline \multicolumn{2}{|c|}{ Socioeconomic Characteristics } & \multirow{2}{*}{$\begin{array}{c}\text { The Number } \\
\begin{array}{c}112 \\
131\end{array}\end{array}$} & \multirow{2}{*}{$\begin{array}{c}\% \\
46.09 \\
53.91\end{array}$} & \multirow{2}{*}{$\begin{array}{c}\text { Urban (179) } \\
82 \\
97\end{array}$} & \multirow{2}{*}{$\begin{array}{c}\% \\
45.81 \\
54.19\end{array}$} & \multirow{2}{*}{$\begin{array}{c}\text { Rural (64) } \\
30 \\
34\end{array}$} & \multirow{2}{*}{$\begin{array}{c}\% \\
46.88 \\
53.13\end{array}$} \\
\hline gender & female & & & & & & \\
\hline \multirow{3}{*}{ age } & under 20 years old & 3 & 1.23 & 2 & 1.12 & 1 & 1.56 \\
\hline & 21-30 years old & 89 & 36.63 & 86 & 48.04 & 3 & 4.69 \\
\hline & $31-40$ years old & 42 & 17.28 & 30 & 16.76 & 12 & 18.75 \\
\hline
\end{tabular}


Table 1. Cont.

\begin{tabular}{|c|c|c|c|c|c|c|c|}
\hline \multicolumn{2}{|c|}{ Socioeconomic Characteristics } & The Number & $\%$ & Urban (179) & $\%$ & Rural (64) & $\%$ \\
\hline & $51-60$ years old & 36 & 14.81 & 18 & 10.06 & 18 & 28.13 \\
\hline & over 60 years old & 16 & 6.58 & 7 & 3.91 & 9 & 14.06 \\
\hline & Total & 243 & 100.00 & 179 & 100.00 & 64 & 100.00 \\
\hline \multirow{4}{*}{ education level } & under junior high school & 5 & 2.06 & 4 & 2.23 & 1 & $1.56 \%$ \\
\hline & high school & 49 & 20.16 & 22 & 12.29 & 27 & 42.19 \\
\hline & college & 134 & 55.14 & 104 & 58.10 & 30 & 46.88 \\
\hline & graduate school & 55 & 22.63 & 49 & 27.37 & 6 & 9.38 \\
\hline & Total & 243 & 100.00 & 179 & 100.00 & 64 & 100.00 \\
\hline \multirow{7}{*}{ profession } & student & 36 & 14.81 & 33 & 18.44 & 3 & 4.69 \\
\hline & household management & 16 & 6.58 & 11 & 6.15 & 5 & 7.81 \\
\hline & government employee & 41 & 16.87 & 32 & 17.88 & 9 & 14.06 \\
\hline & commerce & 33 & 13.58 & 25 & 13.97 & 8 & 12.50 \\
\hline & manufacturing & 24 & 9.88 & 14 & 7.82 & 10 & 15.63 \\
\hline & service industry & 64 & 26.34 & 48 & 26.82 & 16 & 25.00 \\
\hline & others & 29 & 4.12 & 7 & 3.91 & 3 & 4.69 \\
\hline & Total & 243 & 100.00 & 179 & 100.00 & 64 & 100.00 \\
\hline \multirow{5}{*}{ monthly income } & under 20,000 NTD & 61 & 25.10 & 50 & 27.93 & 11 & 17.19 \\
\hline & between 20,000 and 40,000 NTD & 88 & 36.21 & 65 & 36.31 & 23 & 35.94 \\
\hline & between 20,000 and 40,000 NTD & 58 & 23.87 & 36 & 20.11 & 22 & 34.38 \\
\hline & between 40,000 and 60,000 NTD & 19 & 7.82 & 14 & 7.82 & 5 & 7.81 \\
\hline & more than 60,000 NTD & 17 & 3.70 & 7 & 3.91 & 2 & 3.13 \\
\hline
\end{tabular}

\subsection{Selecting Attribute Sets}

The attributes and levels of attributes for local coffee are presented in Table 2. Thus, the number of possible combinations of attributes was $324(3 \times 3 \times 3 \times 3 \times 4=324)$; too many for consumers to choose from. In order to reduce the number of possible alternatives and to help respondents avoid feeling that the questionnaires were lengthy, the number of combinations was reduced by orthogonal design [29]. The orthogonal design procedure in SPSS is used to generate 16 orthogonal arrays for the development of the choice sets. After 16 orthogonal arrays are generated, they are randomly assigned into four groups listed in Table 3. In addition, an alternative set which best fits the real status includes the features of acidic, floral aroma, traditional architecture, and general packaging at a cost of $1200 \mathrm{NTD} /$ pound is used as a basis for comparison with the others previously mentioned. Therefore, there are four choice tasks. In the survey, the respondents were required to choose four tasks listed in Table 3. Each task contained a combination of five alternatives (the reference group is one alternative set of attributes to each choice set).

Table 2. The setting of the attributes of locally grown boutique coffee

\begin{tabular}{ccc}
\hline Attributes $Z_{j}$ & \# of Attributes & Attributes Level \\
\hline Acidity & 3 & no, acid, strong acid \\
Extra scent & 3 & floral, fruity, nutty \\
Café style & 3 & traditional architecture, natural scenery, creative personality \\
Packaging features & 3 & general packaging, local culture, hand-painted design \\
Price/pound (lb.) & 4 & 1000 NTD, 1200 NTD, 1400 NTD, 1600 NTD \\
\hline
\end{tabular}

Table 3. The choice sets.

\begin{tabular}{cccccc}
\hline Choice Sets & Acidic & Extra Aroma & Café Style & Packaging Features & Price/lb. (NTD) \\
\hline (A) & acidic & floral & traditional architecture & general packaging & 1200 \\
1B & none & nutty & traditional architecture & local culture & 1400 \\
1C & acidic & floral & natural scenery & local culture & 1200 \\
1D & acidic & floral & traditional architecture & general packaging & 1400 \\
1E & none & fruity & natural scenery & general packaging & 1400 \\
(A) & acidic & floral & traditional architecture & general packaging & 1200 \\
2B & none & floral & creative personality & local culture & 1000 \\
2C & none & nutty & traditional architecture & hand-painted & 1200 \\
2D & none & floral & traditional architecture & general packaging & 1000 \\
\hline
\end{tabular}


Table 3. Cont.

\begin{tabular}{cccccc}
\hline Choice Sets & Acidic & Extra Aroma & Café Style & Packaging Features & Price/lb. (NTD) \\
\hline 2E & acidic & nutty & creative personality & general packaging & 1600 \\
(A) & acidic & floral & traditional architecture & general packaging & 1200 \\
3B & strong acidic & floral & creative personality & hand-painted & 1400 \\
3C & strong acidic & nutty & natural scenery & general packaging & 1000 \\
3D & none & floral & traditional architecture & general packaging & 1600 \\
3E & acidic & fruity & traditional architecture & hand-painted & 1000 \\
(A) & acidic & floral & traditional architecture & general packaging & 1200 \\
4B & none & fruity & natural scenery & general packaging & 1200 \\
4C & none & floral & natural scenery & hand-painted & 1600 \\
4D & strong acidic & floral & traditional architecture & general packaging & 1200 \\
4E & strong acidic & fruity & traditional architecture & local culture & 1600 \\
\hline
\end{tabular}

\subsection{Theoretical Basis of the Choice Method}

This study uses a discrete choice method to investigate consumers' potential preferences and willingness to pay for different attributes of premium, local coffee [30-34]. By using a random utility model, a discrete choice method is developed to empirically estimate consumer willingness to pay for different attributes of locally grown coffee. Recently, the discrete choice method has been widely used to measure the monetary value of non-market goods [35-37]. Random utility models are used in the discrete choice method to explore consumer preferences. In this model, consumers compare different sets of attributes; then make a choice which relates to their anticipated satisfaction to be generated by the particular attribute set. The probability that a consumer chooses a set of attributes is positively related to the utility that is to be generated [38]. Eventually, this indicates that a set which generates the highest utility will be chosen [39]. According to random utility theory as suggested by Hanemann [40], the utility that product $(j)$ provides for consumer (i) can be represented as follows:

$$
\begin{gathered}
U_{i j k}=\sum \sum_{Z_{j k} \in \tau} \beta_{j k} Z_{j k}+\varepsilon_{i} \\
i=1,2, \ldots, \mathrm{N} ; j=1,2, \ldots, \mathrm{J} ; k=1,2, \ldots, K
\end{gathered}
$$

where, $U_{i j k}$ is the respondent's indirect utility from an alternative $\tau, Z_{j k}$ are the $k$ th attribute level of attribute $j$, and $\beta_{j k}$ are the coefficients of variable attribute level; $\varepsilon_{i}$ is a random term

Variables of attribute levels of locally grown coffee are defined using effect codes [41,42] instead of dummy variables. When there are three attribute levels, the effect codes are created as $(1,0),(0,1)$, and $(-1,-1)$. When setting effect codes in this way, the reference category is not incorporated into the intercept. The effect code for the referenced category is equal to the negative sum of the other two categories. In this study, consumer preference attributes are divided into four preference dimensions, with the characteristics of attribute variables being described as following.

\subsubsection{Acidity}

The acidity attribute comprises three levels: None, acidic, and strong acidic. None and strong acidic are denoted as (A1) and (A2), while their effect coding is $(1,0),(0,1)$, respectively; acidic is set as the reference category with the effect coding of $(-1,-1)$.

\subsubsection{Extra Aroma}

The extra aroma attribute comprises three levels: floral, fruity, and nutty. The fruity fragrance (E1) and the nutty fragrance (E2) are denoted. The encoding for (E1) and (E2) are $(1,0),(0,1)$, respectively. Based on the consideration of the currently common commercially available coffee products, the floral fragrance is set as the reference category, encoded as $(-1,-1)$. 


\subsubsection{The Café Style}

The café style attribute is comprised of three ambiance settings: traditional architecture, natural scenery, and creative personality. Two variables, natural landscape (F1) and creative personality (F2) are denoted with encoding settings as $(1,0),(0,1)$, respectively. Traditional architecture is set as the reference category and is coded as $(-1,-1)$.

\subsubsection{Featured Packaging}

The featured packaging attribute comprises three attributes: general packaging, local culture, and hand-painted design. Local culture (S1) and hand-painted design (S2) are represented as $(1,0)$, $(0,1)$, respectively. The generic or general packaging will be set as the reference category, encoded as $(-1,-1)$.

\subsubsection{Price}

There are four price levels: 1000, 1200, 1400, and 1600 New Taiwan Dollars (NTD) per lb.

\subsection{Modeling Approach}

In this research, the probity model for respondents' choices from a choice set is defined as (2). When the utility of respondent $i$ from product $j$ is higher than that of product $h$, which implying $\mathrm{U}_{i j}>\mathrm{U}_{i h}(j \neq h)$, then subject $i$ selected $j$ from choice set $C$, The probability of choosing the product $j$ can be expressed as:

$$
\begin{aligned}
\mathrm{P}_{i j}\left(\mathrm{Z}_{j} \mid j, h \in C\right) & =P\left(\mathrm{U}_{i j}>\mathrm{U}_{i h} ; j \neq h \in C\right) \\
& =P\left[\left(\mathrm{~V}_{i j}+\varepsilon_{i j}\right)>\left(\mathrm{V}_{i h}+\varepsilon_{i h}\right) ; j \neq h \in C\right] \\
& =P\left[\varepsilon_{i h}-\varepsilon_{i j}<\left(\mathrm{V}_{i j}-\mathrm{V}_{i h}\right) ; j \neq h \in C\right]
\end{aligned}
$$

The stochastic term in $\varepsilon_{i j}$ in (2) are iid and follow type I extreme value distribution. The function form of $V_{i j}$ can be shown by the deterministic (non-stochastic) part of $U_{i j}$ in Equation (1). Therefore, the distribution function of type I extreme value distribution is represented as following:

$$
\mathrm{P}_{i j}=\frac{\exp \left(\mathrm{V}_{i h}\right)}{\sum_{j=1}^{J} \exp \left(\mathrm{V}_{i j}\right)}
$$

If respondent $i$ has to choose from a choice set, and in each choice set, there are five alternatives; the likelihood of sample outcomes can be represented as:

$$
\mathrm{P}_{c i j}=\prod_{j=1}^{5} \frac{\exp \left(\mathrm{V}_{i j}\right)}{\sum_{h=1}^{5} \exp \left(\mathrm{V}_{i h}\right)}
$$

We use a conditional-logit methodology [20] to estimate the random utility model from Equation (1). The decision variables denote whether or not a respondent chooses attribute set $j$ from five alternatives in choice task $C$. If yes, the decision variable $Y_{C i j}$ is set to be 1 , otherwise, $Y_{C i j}$ is 0 . We survey 243 respondents, a total of 972 observations available for our empirical estimations. A conditional-logit model is used to estimate the coefficients in Equation (1). The likelihood function is represented as follows:

$$
\mathrm{L}=\prod_{i=1}^{243} \prod_{\mathrm{C}=1}^{5} P_{\mathrm{Ci1}}^{Y_{\mathrm{C} i 1}} P_{\mathrm{Ci2}}^{Y_{\mathrm{C} i 2}} P_{\mathrm{Ci3}}^{Y_{\mathrm{C} i 3}} P_{\mathrm{C} i 4}^{Y_{\mathrm{C} i 4}}
$$

where $\mathrm{P}_{C i j}$ is the probability that respondent $i$ chooses attribute set $j$ in experiment $C$. 
The willingness to pay (X) for changing attribute level (from attribute level $i$ to attribute level $j$ ) can be derived by the following equation: [39]

$$
\text { partworth }_{j}+\gamma(\mathrm{p}+\mathrm{X})+e_{i}=\text { partworth }_{i}+\gamma \mathrm{p}+e_{j}
$$

By taking expectation of both sides of Equation (6), we have the following:

$$
\begin{gathered}
\text { partworth }_{i}-\text { partworth }_{j}=\gamma E(X)+E\left(e_{i}\right)-E\left(e_{j}\right) \\
E\left(e_{i}\right)-E\left(e_{j}\right)=0
\end{gathered}
$$

Therefore, the expectation of willingness to pay for changing from attribute level $i$ to level $j$ is:

$$
\mathrm{E}(\mathrm{X})=-\frac{\text { partworth }_{j}-\text { partworth }_{i}}{\gamma}
$$

where $p$ is the price level, $\gamma$ is the coefficient of price level, $\mathrm{X}$ is consumer's willingness to pay for changing from attribute level $i$ to attribute level $j, e_{i}$ and $e_{j}$ are error terms with mean zero.

The difference in partworths between attribute level $i$ and $j$ can be estimated by using the coefficients of attribute levels in Table 3.

The parameters in Equation (1) will be estimated by the maximum likelihood method. Substituting the estimated parameters into Equation (7), the consumer willingness to pay for changing attributes of locally grown coffee is determined. These results can be used to represent the latent preference for different attribute levels.

\section{The Empirical Results}

The estimation results of the conditional logit model are presented in Table 4.

Table 4. The empirical results of the conditional-logit model

\begin{tabular}{cccc}
\hline Attributes & Variables & Coefficient & Estimated Partworths \\
\hline \multirow{2}{*}{ acidic } & none (A1) & $0.314^{* * *}$ & 0.314 \\
& strong acidic (A2) & $-0.439 * * *$ & -0.439 \\
extra-aroma & acid(-A1- A2) & 0.125 \\
& floral (E1) & 0.0328 & 0 \\
café style & nutty (E2) & 0.0489 & 0 \\
& natury(-E1- E2) & 0.0787 & 0 \\
featured pcenery (F1) & $0.1960^{* *}$ & 0.0787 \\
& creative personality (F2) & 0.1960 \\
& traditional architecture(-F1- F2) & & -0.2747 \\
price & local culture (S1) & $0.213^{* * *}$ & 0.213 \\
& hand-painted design (S2) & $0.263^{* * *}$ & 0.263 \\
& generic packaging (-S1- S2) & & -0.478 \\
price (P) & $-0.000953 * * *$ & -0.000953 \\
\hline
\end{tabular}

$* * *$ significant at $1 \%$ confidence level; ${ }^{* *}$ significant at $5 \%$ confidence level; McFadden Psuedo $\mathrm{R}^{2}=0.04, \mathrm{LR}=$ 212.9966.

The Wald test statistic for goodness of fit is 212.6; this indicates that the model can explain the utility level of respondents well. The coefficients of attribute levels flora, nutty and fruity are non-significantly different from zero.

By Equation (7), if we want to derive the willingness to pay for changing from attribute level acid to non- acid, from Table 4, the partworth of attribute acid is 0.314 ; the partworth for attribute level none acid is 0.125 . So the willingness to pay for changing from attribute level acid to attribute level non-acid is $-(0.125-0.314) /-0.000953=197$ NTD. Similarly, the willingness to pay for the changing from attribute level general packaging to attribute level local culture is 724 NTD. Therefore, the willingness to pay for changing from reference alternative $1 \mathrm{~A}$ to alternative $1 \mathrm{~B}$ is 921 , which is listed in Table 5. 
Table 5. Consumer willingness to pay for different attribute sets.

\begin{tabular}{cccccc}
\hline $\begin{array}{c}\text { Attribute } \\
\text { Combination }\end{array}$ & Acid & Extra Aroma & Café Style & Featured Packaging & $\begin{array}{c}\text { Willingness to Pay for } \\
\text { Changing from } \\
\text { Reference Group }\end{array}$ \\
\hline Reference group (A) & acidic & floral & traditional architecture & generic packaging & 0 \\
1B & none & nutty & traditional architecture & local culture & 921 \\
1C & acidic & fruity & natural scenery & local culture & 930 \\
1D & acidic & floral & traditional architecture & generic packaging & 0 \\
1E & none & fruity & natural scenery & generic packaging & 403 \\
2B & none & floral & creative personality & local culture & 1333 \\
2C & none & nutty & traditional architecture & hand-painted design & 973 \\
2D & none & floral & traditional architecture & generic packaging & 197 \\
2E & acidic & nutty & creative personality & generic packaging & 412 \\
3B & strong acidic & floral & creative personality & hand-painted design & 595 \\
3C & strong acidic & nutty & natural scenery & generic packaging & -387 \\
3D & none & floral & traditional architecture & generic packaging & 197 \\
3E & acidic & fruity & traditional architecture & hand-painted design & 776 \\
4B & none & fruity & creative personality & generic packaging & 609 \\
4C & none & floral & natural scenery & hand-painted design & 1179 \\
4D & strong acidic & floral & traditional architecture & generic packaging & -593 \\
4E & strong acidic & fruity & traditional architecture & local culture & 131 \\
\hline
\end{tabular}

The retailers will consider all attributes while they develop their marketing strategies for the niche market. Therefore, in this study, consumers' willingness to pays for changing from reference alternative to 16 possible alternatives are presented in Table 5 .

The 16 alternatives obtained by the orthogonal design process method are used. The difference between consumers' willingness to pay for the attribute combinations and reference set are calculated. The highest difference is for the $2 \mathrm{~B}$ alternative (none-floral aroma-creative personality-local culture). The second highest is for alternative 4C (none-floral aroma-natural scenery-local culture-hand-painted design). These two alternatives do not contain acid and include the café styles and featured packaging that consumers are willing to pay more for.

\section{Management Implication}

\subsection{For Local Consumers, the Acidity Is Still the Main Consideration and Preferred Natural Aroma}

The acidity of coffee in absence of sugar or creamer presents the degree of acidity of the coffee itself or the difference in baking. The empirical results show that the respondents are willing to pay an additional 197 dollar (per pound) for the "acid-free" attribute as compared to "acid," attribute, and the attribute "strong acid" is 593 dollar (per pound) less in comparison with the attribute acid. This result is in line with coffee specialists' understanding of the tastes of Taiwanese people that prefer less acidity. Therefore, local producers should provide coffee product with appropriate degree of acid according to the preference of consumers in local specialty niche market.

Consumers are not willing to pay premium for the attributes levels of extra aromas. The respondents stated that if the coffee has extra aromas, the aromas are not considered to be from coffee itself. The extra aromas are deemed artificial. It is not acceptable by consumers preferring the quality of naturally-made and who care about their health. In addition, it is possible due to the reason that consumers are innocent in experiencing the actual aroma and no professional commentator provides detailed explanations, therefore, it has resulted in that consumers do not prefer the attribute of extra aroma. For those who want to develop a marketing strategy for the specialty coffee in the niche market, using actual experiencing to convey the characteristics of coffee is recommended. It is advised to provide professional commentating service in the café.

\subsection{Innovation and Unique Design Will Be the Trend of Future Market Differentiation Strategy.}

For the attribute levels of "café-style", consumers are willing to pay an additional 512 dollars (per pound) for "creative individual architecture" as compared to traditional architecture, and the consumers' willingness to pay between the attributes "natural landscape architecture" and "traditional 
architecture" is 206. For the attribute "packaging features", consumers are willing to pay 724 dollars and 776 dollars (per pound) respectively to levels of attributes "local culture" and "hand-painted" in comparison with "general packaging".

From these results we can see that if external "hand-painted" properties with innovation, creativity, or elements connected to local culture and local style are provided, it is possible to increase the added value of the coffee product. The idea of unique creative ideas is not bound, as long as the characteristics properly integrate special elements or innovative design ideas are provided, it is possible to attract consumers' attention. This result has very important implications in creating advantages in a niche market where smallholder farmers or entrepreneurs can manage themselves to exploring the need and demand from a large number of consumers, and then using their own ideas to create market differentiation. The retailer and whole sellers in the global supply chain are lacking the ability to this adjustment. They are not possible to adjust their quality according to the preference of Taiwanese consumers. Therefore, there is a competition advantage for local producers.

\section{Conclusions and Future Research}

In this research, a discrete choice method was used to investigate the preferences of consumers in Taiwan for different attributes of locally grown coffee. The survey for collecting the data was conducted between April and May in 2015 in Taichung area in Taiwan.

The empirical results showed that the café-style attributes of natural scenery and creative personality were preferred by consumers of local, high-end coffee; packaging which features local culture and hand-painted designs had a positive price premium for local coffee. Furthermore, consumers did not prefer local coffee with strong acidic tastes and extra aroma scents.

As the local coffee industry is expanding, the need for market segmentation and traceability is increasing. The label of origin could be used for market segmentation between locally grown and imported coffee. Therefore, the future research regarding labeling of origin for locally grown coffee is essential. In addition, other labeling used for market differentiation such as bio labeling, organic labeling, and social labeling have shown to be preferred and of higher value to Western consumers. Further, sustainable development in rural areas can be more greatly bolstered in collaboration with the local coffee industry in Taiwan. In the future research, consumers' willingness to pay for local labels of origin has to be estimated going forward, in order to evaluate whether such a promotional policy would be economically viable.

The producers/processors of local grown coffee should adjust their production processes in order to dynamically adjust to and fulfill consumer preferences. For example, there are three main processes pursued in local Taiwanese coffee making; natural or dried in the fruit process, honey process, and washed process. In future research, consumer preference for these processing methods should also be investigated.

Author Contributions: J.-W.W., C.-Y.K. and Y.-C.Y. conceived and designed the experiments; J.-W.W., C.-Y.K. and Y.-C.Y. performed the experiments; J.-W.W., C.-Y.K. and Y.-C.Y. analyzed the data; J.-W.W., C.-Y.K. and Y.-C.Y. contributed reagents/materials/analysis tools; J.-W.W., C.-Y.K. and Y.-C.Y. wrote the paper.

Funding: This research received no external funding.

Conflicts of Interest: The authors declare no conflicts of interest.

\section{References}

1. Agricultural Bureau, Taichung City Government, Taiwan. Available online: http://www.agriculture. taichung.gov.tw (accessed on 25 May 2018).

2. Chalasani, S.; Shani, D. Exploiting niches using relationship marketing. J. Consum. Mark. 1993, 9, 33-42.

3. Dalgic, T.; Leeuw, M. Niche marketing revisited: Concept, applications and some European cases. Eur. J. Mark. 1994, 28, 39-55. [CrossRef] 
4. Garver, M.S. A maximum difference, scaling application for customer satisfaction researchers. Int. J. Mark. Res. 2009, 51, 481-500.

5. Geraghty, S.; Torres, A.M. The Irish wine market: A market segmentation study. Int. J. Wine Bus. Res. 2009, 21, 143-154. [CrossRef]

6. Hooley, G.J.; Saunders, J. Competitive Positioning: The Key to Market Success; Prentice-Hall: Upper Saddle River, NJ, USA, 1993.

7. Kotler, P. Marketing Management, 4th ed.; Prentice- Hall: Upper Saddle River, NJ, USA, 1980.

8. Piercy, N. Market-Led Strategic Change: Making Marketing Happen in Your Organization; HarperCollins: Broadway, NY, USA, 1991.

9. Stanton, W.E.J.; Etzel, J.M.; Walker, J.B. Fundamentals of Marketing; McGraw-Hill: New York, NY, USA, 1991.

10. Zhu, H.; Wang, Q.; Yan, L.; Wu, G. Are consumers what they consume? - Linking lifestyle segmentation to product attributes: An exploratory study of the Chinese mobile phone market. J. Mark. Manag. 2009, 25, 295-314.

11. Hawkins, D.I.; Best, R.J.; Coney, K.A. Consumer Behavior: Building Marketing Strategy, 9th ed.; McGraw-Hill Education: New York, NY, USA, 2003.

12. Keegan, W.; Moriarty, S.; Duncan, T. Marketing; Prentice-Hall: Englewood-Cliffs, NJ, USA, 1992.

13. McKenna, R. Marketing in an age of diversity. Harv. Bus. Rev. 1988, 9, 88-95.

14. Wan, J.W.; Yang, Y.C.; Huang, W.S. An empirical analysis of consumer willingness to pay for domestically grown product attributes: The case of Taiwan. China Agric. Econ. Rev. 2016, 8, 215-229. [CrossRef]

15. Preiss, P.; Charão-Marques, F.; Wiskerke, J.S. Fostering sustainable urban-rural linkages through local food supply: A transnational analysis of collaborative food alliances. Sustainability 2017, 9, 1155. [CrossRef]

16. Copulsky, J.R.; Wolf, M.J. Relationship marketing: Positioning for the future. J. Bus. Strategy 1990, 11, 16-20. [CrossRef] [PubMed]

17. Durham, C.A.; Roheim, C.A.; Pardoe, I. Picking apples: Can multi-attribute ecolabels compete? J. Agric. Food Ind. Organ. 2012, 10, 1-28. [CrossRef]

18. Baier, D.; Pełka, M.; Rybicka, A.; Schreiber, S. Ratings-/rankings-based versus choice-based conjoint analysis for predicting choices. In Data Science, Learning by Latent Structures, and Knowledge Discovery; Springer: Berlin/Heidelberg, Germany, 2015; pp. 205-216.

19. Green, P.E.; Srinivasan, V. Conjoint analysis in consumer research: Issues and outlook. J. Consum. Res. 1978, 5, 103-123. [CrossRef]

20. McFadden, D. Conditional logit analysis of qualitative choice behavior. In Frontiers in Econometrics; Zarembka, P., Ed.; Academic Press: San Diego, CA, USA, 1973.

21. Louviere, J.J.; Flynn, T.N.; Carson, R.T. Discrete choice experiments are not conjoint analysis. J. Choice Model. 2010, 3, 57-72. Available online: http:/ / www.econ.ucsd.edu/ rcarson/papers/LFCJofCM10.pdf (accessed on 1 June 2018). [CrossRef]

22. Jervis, S.M.; Lopetcharat, K.; Drake, M.A. Application of ethnography and conjoint analysis to determine key consumer attributes for latte-style coffee beverages. J. Sens. Stud. 2012, 27, 48-58. [CrossRef]

23. Arnot, C.; Boxall, P.C.; Cash, S.B. Do ethical consumers care about price? A revealed preference analysis of fair trade coffee purchases. Can. J. Agric. Econ. 2006, 54, 555-565. [CrossRef]

24. Basu, A.K.; Hicks, R.L. Label performance and the willingness to pay for Fair Trade coffee: A cross-national perspective. Int. J. Stud. 2008, 32, 470-478. [CrossRef]

25. Cranfield, J.; Henson, S.; Northey, J.; Masakure, O. An assessment of consumer preference for fair trade coffee in Toronto and Vancouver. Agribusiness 2010, 26, 307-325. [CrossRef]

26. De Pelsmacker, P.; Janssens, W.; Sterckx, E.; Mielants, C. Consumer preferences for the marketing of ethically labelled coffee. Int. Mark. Rev. 2005, 22, 512-530. [CrossRef]

27. Rotaris, L.; Danielis, R. Willingness to pay for fair trade coffee: A conjoint analysis experiment with Italian consumers. J. Agric. Food Ind. Organ. 2011, 9, 1-22. [CrossRef]

28. Asioli, D.; Næs, T.; Øvrum, A.; Almli, V.L. Comparison of rating-based and choice-based conjoint analysis models. A case study based on preferences for iced coffee in Norway. Food Qual. Preference 2016, 48, 174-184. [CrossRef]

29. Taguchi, G. Performance analysis design. Int. J. Prod. Res. 1978, 16, 521-530. [CrossRef]

30. Hensher, D.A.; Rose, J.M.; Greene, W.H. Applied Choice Analysis: A Primer; Cambridge University Press: Cambridge, UK, 2005. 
31. Louviere, J.J.; Hensher, D.A.; Swait, J.D. Stated Choice Methods: Analysis and Applications; Cambridge University Press: Cambridge, UK, 2000.

32. Train, K.E. Discrete Choice Methods with Simulation; Cambridge University Press: Cambridge, UK, 2009; Available online: http:/ / elsa.berkeley.edu/books / choice2.html (accessed on 1 June 2018).

33. Street, D.J.; Burgess, L. The Construction of Optimal Stated Choice Experiments: Theory and Methods; John Wiley \& Sons: Hoboken, NJ, USA, 2007; Volume 647.

34. Street, D.J.; Burgess, L.; Louviere, J.J. Quick and easy choice sets: Constructing optimal and nearly optimal stated choice experiments. Int. J. Res. Mark. 2005, 22, 459-470. [CrossRef]

35. Wongprawmas, R.; Canavari, M. Consumers' willingness-to-pay for food safety labels in an emerging market: The case of fresh produce in Thailand. Food Policy 2017, 69, 25-34. [CrossRef]

36. Zhllima, E.; Chan-Halbrendt, C.; Merkaj, E.; Imami, D.; Vercuni, A.; Qinami, I. Analysis of consumer preferences for table olives-The case of Albanian urban consumers. J. Food Prod. Mark. 2015, 21, 521-532. [CrossRef]

37. Zhllima, E.; Chan-Halbrendt, C.; Zhang, Q.; Imami, D.; Long, R.; Leonetti, L.; Canavari, M. Latent class analysis of consumer preferences for wine in Tirana, Albania. J. Int. Food Agribus. Mark. 2012, 24, 321-338. [CrossRef]

38. Murray, D.W.; O’Neill, M.A. Craft beer: Penetrating a niche market. Br. Food J. 2012, 114, 899-909. [CrossRef]

39. Burton, M.; Dan, R.; Young, T.; James, S. Consumer attitudes to genetically modified organisms in food in the UK. Eur. Rev. Agric. Econ. 2001, 28, 479-498. [CrossRef]

40. Hanemann, W.M. Welfare evaluations in contingent valuation experiments with discrete responses. Am. J. Agric. Econ. 1984, 66, 332-341. [CrossRef]

41. Bech, M.; Gyrd-Hansen, D. Effects coding in discrete choice experiments. Health Econ. 2005, 14, 1079-1083. [CrossRef] [PubMed]

42. Boxall, P.C.; Adamowicz, W.L.J.; Swait, M.W.; Laviere, J. Comparison of stated preference methods for environmental valuation. Ecol. Econ. 1996, 18, 243-253. [CrossRef] 